\title{
DISCOVERY OF PREHISTORIC REMAINS IN INDIA.
}

(Extract of letter from R. Brocr Footr, Esq., F.G.S., of the Geological Survey of India.)

"You will be interested to hear of a prehistoric discovery lately made by a friend of mine (a Mr. Fraser, a civil engineer in Government employ) near Bellary, namely, of large numbers of celts, rubbing-stones, and pounders, under such circumstances as to leave no doubt that the hills in which they occur were occupied by the manufacturers, who have left numerous very considerable kitchenmiddens behind them, resting on rude terraces constructed among the immense tors and blocks of granite gneiss of which the hills consist.

Their surface-inspection yielded large numbers of the implements and flakes innumerable; the middens themselves ought therefore to be extremely good hunting-ground when they come to be carefully excavated, as I trust they will before very long.

The celts are in all stages, from the rudest and most palæolithic chipped implement to the completely polished type. The majority are, I think, only polished in part, at the edge. Nearly all are made of Greenstone, which does not occur within several miles of one locality discovered by Mr. Fraser, but a large dyke of which traverses the other.

Of the rubbing-stones most are made of granitic rock, many of a variety totally different from that forming the hill-range.

The round pounding-stones are mostly made of Greenstone.

I had the good luck to discover a third settlement a few days after Mr. Fraser had shown me the two localities he had found. Mine is some 15 or 16 miles west of Bellary. It is a large conical mound, consisting chiefly of soft yellowish slag, in layers, interstratified with the midden-stuff, as shown by many little rain-sections. By-thebye it has been described somewhere already as a volcanic ash-cone!

Being on the march, and the place a very long way from my next stage, I could only devote a very brief space of time to it, but, in a few minutes, I had obtained a polished celt, some pounders, and rubbing-stones, not to mention flakes. One pounder is made of very hard rich red hrematite. The celt is of Greenstone; it has been burnt. The settlement was very likely burned down at several intervals-an occurrence not rare at the present day in poor villages, where the huts are very largely built of the coarse stiff straw of the Holcus Sorghum."

We hope to hear further particulars of this very interesting discovery from Mr. Bruce Foote. Edit. Grol. MaG.

\section{THE CYCLAS CLAY OF WEST LANCASHIRE.}

Sin,--In your last Number, Mr. T. M. Reade denies the existence of a fresh-water clay underlying the peat of the West Lancashire lowland plain, and seems to be under the impression that $I$ never recognized the existence of a Lower Scrobicularia Clay, occupying a . similar position, until the appearance of his papers, and appears to suggest that I should adopt his names of "Washed-Drift Sand" and 